\title{
The Fourth Industrial Revolution and education
}

The inauguration of one of the world's leading specialists in artificial intelligence (Al) as the Vice Chancellor of a South African university has brought the Fourth Industrial Revolution to the fore in the local media and raised interest in what the Fourth Industrial Revolution might mean for education in general - and for post-school education in particular. A fusion of technologies that is blurring the lines between the physical, digital and biological domains, Al's precise beginning is not clear, but it was certainly in evidence 3 years ago, if not earlier, building on the digital revolution.

The implications of the Al revolution for business, industry and daily life remain to some extent in the realm of speculation, but have nevertheless been discussed widely. Just what it might mean for education has had less attention, although the implications are extensive - both in terms of what universities can (or should) contribute to the advance of $\mathrm{Al}$ and its applications and how curricula and learning will need to change.

The most obvious matters are those that relate to the ways in which the nature of work and the job market are changing - and will continue to change at an increasing pace. It no longer makes sense to ask children what they would like to 'do' when they grow up. By the time they enter the world of work, a large portion of current job types will have disappeared, and as many (if not more) jobs, presently not defined, will have become both every day and essential. Apart from the nature of work, there is considerable disagreement as to whether or not the Fourth Industrial Revolution will create more employment or result in the loss of work opportunities.

Optimistic predictions, based on trends already measured, suggest that the next 3 years will see half a million more jobs created than those lost. As the global economy moves towards the widespread adoption of $\mathrm{Al}$ solutions, competition will grow for employees who have the scarce skills required to implement, manage and work alongside the new technology. Developing these skills is therefore vital for any young person wishing to remain relevant in an increasingly automated workplace. ${ }^{1}$

As this skilled workforce supports the Al industry, the demand for even more highly trained professionals will grow accordingly. Workplaces will require adaptable people whose jobs are reimagined, enriched or facilitated by the technology they work alongside. ${ }^{1}$

The pessimistic view is that Al will replace more jobs than it will create - with more than half of today's jobs becoming automated within the next 35 years. This view might, however, prove to be overly pessimistic. For example, the Economist reported recently that while computers can play chess better than almost all human beings, and help to diagnose diseases, excelling at abstract, cognitive tasks and at completing repetitive manual tasks, they are not yet as competent as people when it comes to undertaking non-repetitive physical tasks such as navigating randomly cluttered rooms or assembling pre-made furniture. ${ }^{2}$ This will undoubtedly change in time, but it will be the pace of that change that determines the rate at which such tasks no longer need human engagement.
The implications that arise for institutions of education are at least twofold. Firstly, researchers in relevant disciplines face the challenge of making Al increasingly more sophisticated and useful, not just in manufacturing or planning but also in the direct service of society. The work of scientists, policymakers, social workers, educationists and many others whose duty of care it is to aim for the achievement of the 17 Sustainable Development Goals can all benefit from sophisticated Al applications. Whether the goal is quality education, decent work, climate action, affordable and clean energy or sustainable cities, there are already Al options of value and importance, yet more can and should be developed. But there are also other ways in which research (perhaps of a different nature) is important. In the realms of voice and facial recognition, for example, current systems are based on American and European norms, so that (for example) African or Chinese accents or facial features remain marginal. Al needs to be revolutionised and deracialised - and this requires research and interventions from scholars and scientists, a new activism, that goes beyond the creation of new algorithms. ${ }^{3}$

The second implication has to do with curricula, teaching and learning - rather than about robotic tutors. To succeed as a member of society, and as an employee, in the era of the Fourth Industrial Revolution, numeracy, literacy and an understanding of how the world operates are all essential. Students studying the basic and applied sciences need also to understand the political and social natures of the world in which they live. For the same reasons, students who study the humanities and social sciences need to understand at least the foundations on which $\mathrm{Al}$ is based and operates. This is a different kind of decolonisation of curricula - even requiring, perhaps, some of the elements of the kind of education provided (at least at first-year level) by liberal arts colleges.

The second implication has further requirements: people must have the skills required to implement, manage and work with the new technology, and with one another. And, not least, to be problem solvers, to be adaptable, and to be able to express themselves in both the written and spoken word - and to make the kinds of ethical and moral decisions that are not ever likely to become successful elements of Al. This challenge is one to which educators will have to rise.

\section{References}

1. Marlin D. Millennials, this is how artificial intelligence will impact your job for better and worse. Forbes. 2018 January 16 [cited 2018 May 03]. Available from: https://www.forbes.com/sites/danielmarlin/2018/01/16/ millennials-this-is-how-artificial-intelligence-will-impact-your-job-for-betterand-worse/\#164ba5e44533

2. The Kamprad test: IKEA furniture and the limits of Al. The Economist. 2018 April 21; Leaders. Available from: https://www.economist.com/news/ leaders/21740735-humans-have-had-good-run-most-recent-breakthroughrobotics-it-clear

3. Marwala T. Tackling bias in technology requires a new form of activism [webpage on the Internet]. c2018 [cited 2018 May 03]. Available from: https://www.uj.ac.za/newandevents/Pages/Opinion-Tackling-bias-intechnology-requires-a-new-form-of-activism.aspx 